\title{
Recomendaciones sobre salud bucal en infantes y preescolares. Revisión de literatura.
}

\section{Oral health recomendations for infants and preschoolers. Literature review.}

\author{
Od. Esp. Romo-Cardoso Adriana ${ }^{1 *}$, Espinosa-Orellana Karelys ${ }^{2}$, Sarmiento-Mariño Daniela ${ }^{1}$, Valdez-Zambrano \\ Vianca $^{1}$ \\ ${ }^{1}$ Docente de la carrera de Odontología de la Universidad Católica de Cuenca. Cuenca (Ecuador). \\ ${ }^{2}$ Estudiante, Carrera de Odontología de la Universidad Católica de Cuenca. Cuenca (Ecuador). \\ *adrianaromoc@hotmail.com
}

\begin{abstract}
Resumen
El propósito de revisión narrativa de la literatura es que sirva de guía para que el odontólogo pueda dar a conocer a los padres y pacientes que se atienden en clínicas odontológicas sobre la importancia de la salud bucal y las recomendaciones para su mantenimiento en la población pediátrica. La salud bucal es un factor fundamental para prevenir enfermedades sistémicas, hábitos nocivos a nivel oral, mejorar la calidad de vida, la misma que debe ser tratada desde la fase de gestación, controlando el crecimiento y desarrollo del niño. La revisión bibliográfica y contraste de información realizada por el grupo de autores de este artículo, permitieron se identifique el valor que tiene la oportuna atención bucal de niñas y niños. Se encontró información que respalda contundentemente la idea de la necesidad de planes sociales públicos y privados que favorezcan la promoción de salud y prevención de enfermedad en lo que a salud bucal refiere.
\end{abstract}

Palabras clave: Salud bucal, gestación, infancia, cuidado, prevención, nutrición.

\begin{abstract}
The purpose of this review article is to collect evidence about the importance of oral health and recommendations for its maintenance in the pediatric population. Oral health is a fundamental factor to prevent systemic diseases, harmful habits at the oral level, improve the quality of life, the same that must be treated from the gestation stage, control the growth and development of the child. The bibliographic review and the contrast of information carried out by the group of authors of this article allow us to identify the value of the opportunity for oral care of children. Information was found that strongly supports the idea of the need for public and private social plans that favor health promotion and disease prevention in terms of oral health.
\end{abstract}

Key words: Oral health, pregnancy, childhood, care, prevention, nutrition.

\section{INTRODUCCIÓN}

Una de las consultas más frecuentes que realizan los padres de los pacientes niños es acerca de las medidas de prevención y cuidado que se deben tener para evitar las enfermedades bucales, al respecto el odontólogo tiene que poder guiar a los pacientes con información basada en evidencia, el presente artículo tiene la finalidad de recopilar una serie de recomendaciones que el odontólogo, estudiante de la profesión o personal de salud, puede alcanzar a los pacientes como parte de la educación que se desarrolla dentro de la actividades de promoción de la salud.

Según las teorías de las etapas psico evolutivas, manifiestan, que un infante es considerado dentro del rango de 0 a 18 meses, un bebé entre 18 meses a 3 años y un preescolar de 3 a 5 años de edad.

En los infantes, mantener los dientes sanos es muy importante para su salud general, esto desde el momento del nacimiento, ya que en la actualidad el objetivo en salud oral es tratar de que los niños crezcan libres de enfermedades. Existen diferentes herramientas que se pueden utilizar para promover una buena salud, es por esto que se hace necesario que los padres lleven a sus hijos a chequeos constantes, en si nos enfocamos en los odontólogos, aplicando medidas preventivas para llevar dientes sanos y prevenir futuras lesiones cariosas, entre otras enfermedades que se originan de la mala salud oral en infantes. El cuidado bucal en la etapa infantil es indispensable, empezando desde una adecuada 
nutrición y seguido de esto una buena higiene bucal.

Ante un deficiente cuidado buco dental, se obtendrá una enfermedad que es la caries dental que se la puede definir como una patología multifactorial que agrede a los dientes, en mayor proporción al esmalte, avanzando mas rápido una vez que llega a la dentina. Esta abarca una mayor prevalencia en infantes que están expuestos a alimentos líquidos por un largo periodo de tiempo, debido al biberón o al pecho de su madre, con alto grado de azucares intrínsecos y extrínsecos. Por otro lado, la atención de la salud bucal en los preescolares debe ser el principal objetivo en las políticas de salud pública en todas partes del mundo, estas deben verse manifestadas en programas y proyectos que den resultados efectivos, donde se promocione la educación oral en infantes para así prevenir problemas, en cuanto a la estética, fonética y función masticatoria, lo cual va a repercutir en su aspecto psicológico.

\section{ESTADO DEL ARTE}

\subsection{Salud Bucal}

La salud se determina como un estado de bienestar, físico mental y social, es decir llevar una salud adecuada se convierte en un recurso, el cuidado de los dientes desde la primera dentición favorece su calidad de vida, con beneficios a largo plazo, de lo contario esta se ve afectada por distintas enfermedades empezando por el estado general del niño, siendo la lesión cariosa la más común.

Existen diferentes enfermedades a nivel sistémico como diabetes, trastornos respiratorios e inclusive alteraciones en el embarazo que pueden ser producto de algunas afecciones bucodentales, para favorecer el buen crecimiento y desarrollo del infante y preescolares. ${ }^{1}$

Entre las patologías más comunes que afectan a nivel bucal se ha identificado a la caries dental, que son lesiones muy evidentes en niños menores de cinco años, es por ello la importancia de una respectiva atención odontológica y la promoción de la salud bucal, tratando de concientizar a padres para mejorar hábitos alimenticios y de higiene oral y obtener como resultado una cavidad bucal saludable. ${ }^{2}$

La salud bucal de un infante, inicia a partir del embarazo ya que puede existir una relación entre el estado de la madre gestante con la del estado bucal y general del futuro bebé, lo cual se reflejará en la primera infancia y la niñez. ${ }^{2,3}$ La caries dental, es una de las patologías más frecuentes en infantes, debido a muchos factores, pero sobre todo por el papel fundamental que desempeña la madre gestante en garantizar una buena salud bucal a su bebé, de lo contrario existe un mayor riesgo a adquirirla, ya sea por su alimentación, refiriéndose mayormente al consumo elevado de azucares, las cuales causan controles prenatales, cuidados y las respectivas medidas preventivas que debe tomar su madre. ${ }^{2}$

Según la OMS la relación de caries y el consumo de azucares tiene más relevancia cuando estas son añadidas o ingeridas en confitería, mas no tanto en frutas y verduras orgánicas. ${ }^{2}$

\section{Recomendaciones para la prevención de las enferme- dades bucales}

\subsection{Cuidado dental}

Una buena salud bucal y el control de enfermedades bucales protegen el estado de la mujer embarazada y su calidad de vida. ${ }^{2,3}$ El estado de embarazo, no debe ser un motivo para postergar o retrasar el cuidado dental rutinario o el tratamiento del mismo, al contrario, se deben promover los hábitos saludables que se basen en información veraz, de forma constante e interdisciplinaria entre los diferentes profesionales que están inmersos en el desarrollo y proceso de la madre gestante, como gíneco / obstetras y odontólogos. ${ }^{3}$

La madre gestante deberá realizar visitas rutinarias al dentista y limpiezas profesionales, sus cuidados bucodentales caseros deberán ser mayores, como cepillados con pasta fluorada 2 veces al día y uso de hilo dental cada noche, reducir la carga bacteriana con enjuagues de clorhexidina o gomas de mascar que contengan xilitol, llevar una dieta balanceada y limitarse a la ingesta de azúcares entre comidas. ${ }^{3}$

\subsection{Educación y Estatus Socioeconómico}

Los factores que participan en el desarrollo de las enfermedades bucales en la infancia, particularmente las caries, tienen múltiples determinantes, sin embargo, factores sociales y ambientales han sido obviados sin saber que son factores que también predisponen a un niño a la enfermedad. Los conocimientos de la salud de la boca de los padres, el bajo nivel socioeconómico, hábitos alimenticios incorrectos en familias, insuficiente o nula higiene oral y ausencia de controles profesionales son factores que tienen una influencia directa en la salud bucal en los niños. Es por ello, la necesidad de programas preventivos y educativos para ofrecer la posibilidad de vivir sin enfermedades bucales. ${ }^{3,4}$ Para lograr una salud óptima la clave se centra en los cambios de estilo de vida, cambios en el conocimiento, las actitudes y el comportamiento. Por tal razón, es en el embarazo donde se debe empezar a educar al paciente, por razones como: ${ }^{4}$

- Muchas embarazadas no conocen las normas preventivas de una buena salud bucal.

- Es más sencillo adoptar buenos hábitos antes del nacimiento del bebé, a tratar de cambiarlos cuando el bebé ya haya nacido. 
- Mantener niveles bajos de Streptococcus mutans (bacteria cariogénica), disminuye la transmisión de bacterias y caries en al niño. ${ }^{4}$

Los lugares donde se ofrezcan las pautas preventivas deben incluir estrategias de promoción de la salud general y programas odontológicos educativos, a través de diferentes profesionales y proyectos comunitarios en base a una información consistente y correcta siendo accesibles a todos los niveles socio-económicos. ${ }^{4}$

\subsection{El Cepillado Dental}

El uso de pasta dental fluorada, de acuerdo al riesgo de caries, ofrece un gran beneficio en el cepillado dental para mejorar el estado de los dientes de los niños. El profesional odontólogo es el indicado para hacer una valoración del riesgo de caries de cada persona. Se puede persuadir a los padres para que adopten e implementen estos hábitos dentales positivos. $^{5}$

- Limpieza de la boca del bebé sin dientes. Es importante limpiar la boca del bebé aún antes de que erupcionen los dientes, se deben eliminar los restos de alimentos y placa bacteriana, después de cada toma de líquidos o una vez al día. Se puede utilizar una gasa humedecida, la misma que se pasará suavemente por la mucosa. ${ }^{6}$

- Limpieza de la boca del bebé con dientes. Cuando los dientes empiecen a erupcionar debemos utilizar un dedal de silicona o un cepillo infantil de cerdas muy suaves que sea adecuado a la edad del niño. Esta limpieza la debemos realizar dos veces al día, una en la mañana y otra en la noche, porque durante la siesta el riesgo de caries aumenta, al disminuir la cantidad de saliva en boca. Los padres deben implementar el uso de hilo dental, esto se aplica una vez que exista contacto entre los dientes o molares. Se pueden utilizar flosser, que son posicionadores de hilo dental para un mejor manejo. ${ }^{6}$

Para realizar correctamente un cepillado los padres tienen que:

1) Controlar y supervisar la motricidad del cepillado del niño y la cantidad de pasta dental, de acuerdo al riesgo que está expuesto a padecer lesiones cariosas. El abordaje final del cepillado debe ser realizado por los padres.

2) Comenzar siempre por el mismo lado y realizar el mismo recorrido.

3) Limpiar todas las superficies externas, internas y masticatorias.

4) Cepillar la lengua y carrillos suavemente. ${ }^{6}$

Si se utilizan pastas fluoradas en niños menores de 2 años con alto riesgo de caries, lo pueden hacer, empezando con dentífrico fluorado en una cantidad de 1000 ppm sobre el cepillo dos veces al día. Por otro lado, todos los niños mayores de 2 años deben utilizar de 1000 a 1450 ppm de pasta fluorada para el cepillado dental, lo cual se observa en los ingredientes del dentífrico. ${ }^{6}$

\subsection{Hábitos para la prevención de la caries}

- El niño debe ser alimentado con intervalos adecuados a su edad.

- El contenido del biberón tiene que ser solamente con líquidos no azucarados, mientras está en la cuna.

- Eliminar el uso de biberón y chupón a partir del primer año de edad.

- Cambiar al uso de cuchara y el vaso.

- Cuando los dientes empiecen a erupcionar se debe incorporar comidas sólidas.

- Cepillar los dientes del infante y pre escolares con pasta fluorada.

- Evitar el consumo frecuente de comidas y bebidas azucaradas.

- Llevar un registro del paciente con el odontólogo. ${ }^{7}$

\subsection{Dieta y Nutrición}

Cuando hablamos de dieta hacemos referencia a la ingesta rutinaria de alimentos y bebidas que realiza cualquier persona en su vida diaria. La nutrición es la asimilación de los alimentos y el efecto que tiene sobre los procesos metabólicos del organismo. ${ }^{8}$

Es importante mantener informados a los padres de lo relevante que es el control de dulces y una dieta balanceada en los pequeños, como parte de un programa integral de prevención. ${ }^{8}$

Dentro de las recomendaciones dietéticas tenemos:

- Promover una dieta balanceada, así mismo la limpieza de la cavidad bucal después de haber ingerido algún alimento.

- Combinar alimentos crudos con cocidos.

- Todos los alimentos deben ser ricos en fibra que estimulen la masticación e incluir al final alimentos no cariogénicos.

- Las personas que tienen alto riesgo de caries y baja producción de flujo salival, tienen que cepillar sus dientes antes de cada comida, para impedir el descenso del $\mathrm{pH}$ salival. $^{8}$

\subsection{Nutrición de la madre durante el embarazo}

La madre debe ingerir una mayor cantidad y calidad de calorías y minerales, ya que es la proveedora de los nutrientes necesarios para el bebé. ${ }^{2}$ 


\subsection{Lactancia materna y alimentación en la primera infan- cia}

Se sugiere que la lactancia materna sea hasta los seis meses después del nacimiento de manera obligatoria y de ser posible se amplie hasta los 2 años, por los nutrientes que provee. Después de la salida del primer diente es recomendable la introducción gradual de alimentación semisólida. $^{2}$

No "soplar" ni probar alimentos de la misma cuchara porque se produce transmisión horizontal de la principal bacteria cariogénica Streptococcus mutans. ${ }^{2}$

\subsection{Consecuencias de una mala salud bucal}

\subsubsection{Consecuencias en los infantes}

La atención odontológica en el infante se encuentra encaminada hacia el buen cuidado dental, educando a los progenitores, para inculcar hábitos saludables en el niño, los cuales ayuden a impedir las patologías orales. ${ }^{9}$

Por lo general la consulta al odontólogo ocurre una vez que el problema ya está establecido, como molestias dentarias o cuando presenta dolor y múltiples lesiones cariosas. A futuro esto va a implicar tratamientos complejos a una temprana edad, causando traumas en los infantes, por la extensión y complejidad de las lesiones. ${ }^{10,11}$

Por lo general, las caries de biberón o también denominada caries de infancia temprana, es causada por factores como: el amamantamiento incorrecto y prolongado, ingesta frecuente de alimentos que contienen azúcar y sobretodo el biberón con contenido de leche o zumos. ${ }^{7}$

\subsubsection{Impacto de una mala salud bucal en los desempeños diarios de niños}

Dificultades bucales en niños son comunes y pueden interferir de modo significativo en la realización de actividades dentro del hogar, centro educativo y otras actividades. ${ }^{10}$

Las enfermedades bucales en los niños, por lo general se dan como consecuencia de distintas actitudes, entre ellas la más frecuente es la falta de interés en el cuidado e higiene dental, dando como consecuencia enfermedades orales como: ${ }^{10}$

- Lesiones cariosas: es la enfermedad multifactorial más común en niños y niñas, en la cual interactúan distintos factores como, la dieta diaria, el consumo de carbohidratos -que se fermentan en la boca- y agentes microbianos(el Estreptococos mutans la principal bacteria generadora de esta patología junto con los Lactobacillos). Esta comienza a observarse por una mancha blanca, ubicada en la superficie externa del diente y si no es controlada en un periodo corto, causará una cavitación en la pieza dental asociada con dolor. ${ }^{12,13}$

- Halitosis: esta se deberá a una incorrecta higiene bucal, que es la causante del mal aliento, el no usar hilo dental ni cepillarse diariamente facilita el alojamiento de partículas de alimentos entre los dientes, en la lengua y alrededor de las encías, estos restos al descomponerse son los causantes el mal olor en nuestra boca, junto con los desechos del metabolismo que realizan las bacterias en la boca. ${ }^{1}$

Por otro lado estas patologías pueden tener efectos graves, y fijos, que afectan el bienestar del niño. ${ }^{10}$

- Genera dolor e infección, y algunas veces se requiere cirugía y tratamientos costosos, con la consecuente pérdida de actividades diarias y académicas. ${ }^{10}$

- Los niños con caries pueden presentar problemas de confianza en sí mismos debido a la mala apariencia de sus dientes, también vergüenza de hablar o sonreír, dando un resultado negativo en la capacidad de comunicación. $^{10}$

- Un proceso carioso con amplia pérdida de la estructura de la corona dental puede causar dolor durante la función masticatoria, impidiendo recibir los nutrientes necesarios para el cuerpo en crecimiento. ${ }^{10}$

- El dolor constante afecta la capacidad para descansar, se sabe que durante el sueño el cuerpo produce las sustancias necesarias para el crecimiento, en tal sentido las caries profundas tienen un impacto indirecto en el desarrollo del niños. ${ }^{10}$

\section{DISCUSIÓN}

Está claro que el cuidado de la boca es un problema a tener en cuenta desde antes del nacimiento de una persona, las condiciones ambientales (incluidas las del vientre materno) deben ser consideradas incluso durante el periodo de gestación, esto porque después afectarán directamente la aparición y cuidado de las piezas dentales desde las etapas más tempranas del desarrollo.

El cuidado dental, según información obtenida tras investigaciones científicas como la de Osses S, et al, $2014^{6}$ debe adecuarse a la etapa de desarrollo que transita una persona en determinado momento, desde este punto se empieza a evidenciar la necesidad de programas amplios sobre la promoción de salud y también prevención de enfermedad en lo que a esta materia se refiere.

Como manifiesta González-Penagos C, et al, 2013, ${ }^{6}$ existen prácticas específicas como el cepillado dental que 
tienen la cualidad que previenen la aparición de cualquier alteración de la salud bucal, el cepillado forma parte de una serie de hábitos de cuidado que se debe acompañar de una dieta que siempre tome en cuenta la cantidad y calidad de calorías, minerales, alimentos crudos, cocinados y bebidas que formen parte de la ingesta diaria.

Para Freire A, et al, 2016, ${ }^{7}$ la salud bucal durante la niñez merece especial cuidado, sobre todo tomando en cuenta la subestimación que se le da en ocasiones porque generalmente se supone que las niñas y niños no cuentan con dientes permanentes, esto desemboca en que a veces se ignore o pase por alto las consecuencias negativas que pueden surgir de una despreocupación en este ámbito.

Con el paso de los años, según Gonzáles MF, et al, $2014^{8}$ se evidencian los resultados de una buena o mala salud bucal, aparecen diagnósticos como gingivitis, caries, periodontitis o halitosis, que a su vez deben ser identificados y tratados con prontitud, el correcto diagnóstico y el oportuno tratamiento también son tópicos importantes en esta materia.

La infancia es una etapa de vida en la que los hábitos y rutinas se aprenden con más facilidad. Como manifiestan Revello V. e Isler M. en el año $2013^{2}$ si se le da la importancia debida a la salud bucal, conductas como el cepillado dental o la correcta ingesta de alimentos pueden favorecer el entorno de desarrollo de una persona y precautelar el bienestar de muchas otras áreas de la salud general de quien cuida de su organismo.

Aunque se redactó ya en líneas anteriores, es necesario hacer énfasis en la importancia de la planificación e implementación de programas que promuevan las buenas prácticas de salud y también prevengan la aparición de enfermedades. Se debe atacar la cultura de salud/enfermedad manifiesta en nuestro país que espera la aparición de una molestia sintomática, y que sólo a partir de ese momento se interesa por defender el cuerpo de cualquier condición.

Finalmente, la salud bucal de niñas y niños es una tarea que compromete de igual manera a instituciones públicas, profesionales de la salud, familiares y sociedad en general, si la infancia es la etapa de la vida en que una persona aprende a sonreír, también debe ser la etapa en que esa persona aprenda a valorar y cuidar esa sonrisa.

\section{CONCLUSIONES}

Tras el diagnóstico clínico específico, el pronóstico de la salud bucal de un paciente va a depender de la disponibilidad de los profesionales para colaborar conjuntamente con la comunidad y así prevenir dicha enfermedad.
La importancia de una atención interdisciplinaria en las gestantes es esencial para la plenitud de su salud, y crucial para poder informar, orientar y educar a los futuros padres sobre la importancia del cuidado bucal para que exista mayor conocimiento a un cambio de hábitos durante estaa etapa

\subsection{Recomendaciones finales}

La Asociación Internacional de Odontopediatría (IAPD), 2019, recomiendan que la primera atención odontológica se debería recibir cuando el primer diente erupciona o pasando su primer cumpleaños.

En preescolares con riesgo de caries, la importancia radica usar flúor tópico y pasta fluorada, esto debe ser colocado en su cepillo dos veces al día para prevenirla, ya que su función es reducir la placa bacteriana, al momento que las dos se complementan su trabajo es combatir la producción de caries y eliminar la llamada "mancha blanca" de la pieza dentaria para evitar que se convierta en una. ${ }^{6}$

Para mejorar la apariencia dental de los niños y evitar enfermedades bucales, se requiere una correcta higiene dental, por lo que se debe: ${ }^{14}$

- Los padres deberían realizarse el cepillado dental delante de sus niños, ya que ellos son su modelo a seguir. ${ }^{14}$

- Animar a los niños es una manera para cuidar su buena higiene oral, premiándoles por su buen cuidado dental. ${ }^{14}$

- Visitar al dentista regularmente y así ayudar a cuidar sus piezas dentales, es primordial asistir al odontólogo siquiera una vez al año. ${ }^{14}$

- Después de cada comida realizar el cepillado dental, recalcando cepillarse después del desayuno y al momento de dormir, ya que en estas horas es cuando más se genera placa bacteriana. ${ }^{15}$

- Se recomienda utilizar un temporizador para que el cepillado en el niño sea en el tiempo correcto. ${ }^{14}$

- Disminuir alimentos azucarados, dado que provocan caries y perjudican el esmalte dental. ${ }^{15}$

CONFLICTO DE INTERESES: Los autores no manifiesta ningún conflicto de interés.

\section{Referencias Bibliográficas}

1 Conteras N; Valdivieso M; Cabello E. Nivel de conocimientos y prácticas de medidas preventivas de profesionales de salud sobre caries dental en el infante. Rev. Estomatol Herediana. 2008: 18(1):29-34.

2 Perona G, Castillo J. Manejo odontológico materno infantil basado en evidencia científica. 1ra. Ed. Madrid: Editorial Ripano; 2012. 
3 Elkarmi R, Hassona Y, Taimeh D, Scully C. YouTube as a source for parents' education on early childhood cariesInternational. Journal of Paediatric Dentistry 2017; 27: 437-443.

4 Silva J, Araújo A, Costa B, Jones K, Eleutério A. Socioeconomic inequalities in the use of dental care services during early childhood- an epidemiological survey. International Journal of Paediatric Dentistry 2018; 28: 400-409.

5 Fernández C; Carrera C; Muñoz C; Cury J; Giacaman R. Stability of chemically available fluoride in Chilean Toothpastes. International Journal of Pediatric Dentistry 2017; 27:496-505.

6 Barberia, E. Atlas de odontología infantil para pediatras y odontólogos. 2da. Ed. Madrid: Editorial Médica Ripano; 2005.

7 Salete, M. Odontopediatría en la primera infancia. 1ra. Ed. Madrid: Editorial Santos; 2009.

8 Moynihan P, Petersen P. Diet, nutrition and the prevention of dental diseases. The Nutrition Society Advancing Nutritional Science. Feb 2004, Vol 7, Issue 1.

9 Ayala C. Los pediatras en la prevención de enfermedades bucales. Arch. Pediatr. Urug. 2016 Sep; 87( 3 ): 257-262.

10 Raymundo L., Buczynski A., Luiz R., Castro G., Ribeiro I. Impacto de la salud oral en la calidad de vida de los niños pre-escolares: percepción de los responsables. Acta Odontológica Venezolana. 2011. Vol 49, Issue 4.

11 Irigoyen ME, Luengas IF, Yashine A et al. Dental caries experience in Mexican schoolchildren from rural and urban communities. Int Dent J 2000; 50:41-45.

12 Flores M, Montenegro B, Relación entre la frecuencia diaria de consumo de azucares extrínsecos y la prevalencia de caries dental. Rev Estomatol Heredia 2005; 15 (1).

13 McIntryre J. Características y Progresión de la caries dental. En: Mount GJ y Humu WR. Conservación y restauración de la estructura dental. Madrid: Harcourt Brace; 1999.p.10-17.

14 Cisneros G, Hernández Y. La educación para la salud bucal en edades tempranas de la vida. MEDISAN 2011 Oct ; 15( 10 ): 1445-1458.

15 Tan T, Alonso U, Tan N. Educación Comunitaria en Salud Bucal para niños. Rev Hum Med . 2003 Ago; 3( 2 ).

Recibido: 01 de Febrero del 2020

Aceptado: 15 de abril del 2020 